OPEN ACCESS

Edited by: Aaron Williamon,

Royal College of Music, United Kingdom

Reviewed by: Imogen Aujla,

University of Bedfordshire Luton, United Kingdom Glenna Batson, Wake Forest University, United States

*Correspondence: Anita R. Shack dranitashack@gmail.com

Specialty section:

This article was submitted to Performance Science, a section of the journal Frontiers in Psychology

Received: 30 March 2018 Accepted: 18 June 2018 Published: 05 July 2018

Citation:

Shack AR, Meiyappan S and Grossman LD (2018) Improved

Self-Esteem in Artists After

Participating in the "Building Confidence and Self-Esteem Toolbox Workshop". Front. Psychol. 9:1169. doi: 10.3389/fpsyg.2018.01169

\section{Improved Self-Esteem in Artists After Participating in the "Building Confidence and Self-Esteem Toolbox Workshop"}

\author{
Anita R. Shack ${ }^{1 *}$, Soumia Meiyappan ${ }^{2}$ and Loren D. Grossman ${ }^{3}$ \\ ' Al and Malka Green Artists' Health Centre, Toronto Western Hospital, University Health Network, Toronto, ON, Canada, \\ 2 Department of Family and Community Medicine, Toronto Western Hospital, University Health Network, Toronto, ON, \\ Canada, ${ }^{3}$ Faculty of Medicine, University of Toronto, Toronto, ON, Canada
}

Performing and creative artists have unique occupational and lifestyle stresses and challenges that can negatively affect self-esteem. Low self-esteem not only has serious implications for their psychological and physical health, it can also affect their performance, and creativity. There is a need to establish effective interventions to deal with this issue. To the best of our knowledge, there are no reported studies specific to workshops or interventions on enhancing self-esteem for artists. The Al and Malka Green Artists' Health Centre at the Toronto Western Hospital, University Health Network, Toronto, Ontario, Canada, is a unique multidisciplinary, and integrative clinic serving the special needs of the artist population. We developed a workshop entitled "Building Confidence and Self Esteem Toolbox Workshop" to address this need. We then designed a single-blind, randomized, prospective, pilot study to evaluate the effectiveness of the workshop on enhancing self-esteem in artists, and to evaluate the long-term effectiveness of using the recommended tools in maintaining a healthy self-esteem, as well as maintaining physical and emotional health. Both quantitative and qualitative data were collected. A validated "Self-Esteem Checkup" questionnaire was administered preand immediately post workshop, as well as at 2, 6, and 12 months post workshop. Openended questions were posed to study participants via email at 2 and 12 months following the workshop, and at 6 months in in-person interviews. Thirty-five professional artists consented to participate in the study, with 26 completing all study visits. Mean scores for all time points, and the individual questionnaire statement mean scores for the five timepoints increased significantly post-workshop and remained statistically significantly improved by the 3rd follow-up 12 months later $(p<0.001)$. The mean self-esteem rating score increased significantly post-workshop and remained statistically significantly improved by the 3rd follow-up 12 months later $(p<0.01$ ). Qualitative data showed positive feedback on the utilization of the tools learned in the workshop that helped maintain this improvement over a 1-year period. This workshop may be an effective means of addressing the issue of self-esteem in artists. Further controlled studies of larger sample size and longer duration are needed to confirm these findings.

Keywords: self-esteem, artists, workshop, performance, health, transformation 


\section{INTRODUCTION}

Healthy self-esteem, defined as a realistic appreciation of oneself (Schiraldi, 2001), is an important element of psychological and physical health (Hudd et al., 2000; Kenny, 2011; Koban et al., 2017; Buckley, 2018). It serves as a basis and motivation for behavior that encodes positive attitudes, perceptions and selftalk, and provides ways to buffer stress and stabilize oneself in times of intense stress or negative feedback (Pyszczynski et al., 2004; Creswell et al., 2013). Self-confidence is a narrower construct that can be defined as simply believing in oneself (Blascovich and Tomaka, 1991; Benabou and Tirole, 2002).

The association between low self-esteem and stress and increased anxiety, and between high self-esteem and wellbeing are supported in the literature (Abouserie, 1994; Hudd et al., 2000; Sakellari et al., 2018). Negative self-esteem has been associated with serious health issues including eating disorders, social anxiety disorder, and suicide (Kelly et al., 2014; Ianucu et al., 2015; Eades et al., 2018). Elevated levels of stress and low self-esteem can impact one's ability to function, perform, and create (Steptoe, 2001; Brady, 2011). This has significant implications for artists across all disciplines.

Artists have unique occupational and lifestyle stresses and challenges that can negatively impact self-esteem. In addition to dealing with the demands of daily life (interpersonal relationships, finances, time management), they are under pressure to train, practice, perform, produce, create and to cope (van Fenema and van Geel, 2014; Vervainioti and Alexopoulos, 2015). Low self-esteem is a factor in performance anxiety (Langendorfer et al., 2006). This extreme stress experienced by musicians, dancer, and actors can be debilitating and career shortening if not career ending in its effect (Miller and Chesky, 2004; Zwaan et al., 2010). Many artists need to promote and produce their own work. Many are underemployed and/or undercompensated for their artistic work. Low financial status can negatively impact self-esteem (Fabiani et al., 2016; Gardner et al., 2016). The demands on the bodies, minds, and emotions of artists poses health risks and can lead to injuries (Shrier and Hallé, 2011; Rickert et al., 2013). Coping with compromised health and injuries leads to further stresses (O'Dea and Abraham, 2000). Lack of social support from peers, families, friends, educators, and health care providers, is another stress factor contributing to low self-esteem (DeLongis et al., 1988).

Artists' identities are tightly bound to their artistic discipline and pursuits (Parncutt and McPherson, 2002). They live in a world where comparison, competition, and perfectionism are widespread (Mor et al., 1995; Langendorfer et al., 2006; Nordin and McGill, 2009). Literature supports the belief that professional performing and creative artists share a tendency to perfectionism that is associated with low self-esteem and low self-concept, and higher levels of anxiety (Marchant-Haycox and Wilson, 1992; Kenny et al., 2004; Hamilton and Robson, 2006; Bodner and Bensimon, 2008; De Haas and Winterkorn-Pierrot, 2009; Nordin-Bates et al., 2011; Schellenberg, 2011; Simmonds and Southcott, 2012). Studies of music and dance students also support this view (Nordin and McGill, 2009; van Fenema and van Geel, 2014). Those who set excessively high standards for themselves tend to be over critical in self-evaluation, feeling they are never good enough, self-doubt, and anxiety over mistakes (van Fenema and van Geel, 2014). Often being subjected to the extrinsic factors of correction, criticism, judgement, and rejection from family, educators, audiences, critics, agents, curators, producers, directors, choreographers, and peers is part of the artists' reality. This can erode self-esteem and contribute to creating a strong voice to artists' negative inner dialogue. Negative self-talk can seriously affect performance (Parncutt and McPherson, 2002).

Clearly there is a pressing need for healthy coping strategies, empowering self-evaluation tools, support, education, and interventions aimed at addressing the issue of self-esteem in the artist population. The benefits of improved self-esteem for artists can result in a better ability to manage stress, improved physical, and mental health, and enhanced ability to create and perform (Nordin and McGill, 2009).

The Al and Malka Green Artists' Health Centre at the Toronto Western Hospital, University Health Network, Toronto, Ontario, Canada, is a unique multidisciplinary, and integrative clinic. It includes natural and traditional medicine practitioners in a collaborative, holistic, patient centered model serving the special needs of the artist population. This includes performing and creative professional artists from all disciplines (music, theater, dance, film, writing, circus, photography, visual artists, etc.). Over the course of more than 15 years working with these artists, we have observed that many presenting to the clinic for either stress related emotional, psychological or musculoskeletal complaints, had underlying issues of low self-esteem. Educational group workshops designed to address the requests and perceived needs of the artist population are part of the mandate of this clinic. In 2009 there was a request for a workshop to help address self-esteem.

We developed a workshop entitled "Building Confidence and Self Esteem Toolbox Workshop" to address this need. The design of the workshop was intentionally created to take the participants through a transformative experiential journey to facilitate meaningful change. Theoretical knowledge and concepts were taught and discussed to further enhance understanding, help shift view points and belief systems, and support the steps in the experiential process (Branden, 1994; Strikes and Orsi, 1999; Schiraldi, 2001; Kukla, 2007).

The issue of self-esteem is complex and impacts a person in all aspects; physical, emotional, mental, and spiritual. Therefore, a variety of exercises and experiences were included to affect the participants on these levels. Some of these included guided imagery, meditation, writing, partner work, and ceremonial ritual. As part of the journey, participants challenge their current beliefs, assumptions, and perceptions of negative selfesteem, explore where these come from, identify, and learn to manage personal obstacles to attaining a positive self-concept, discover tools to free themselves from being attached to the judgements of others, and to constructively self-evaluate, deal with negative thought patterns, and embrace positive self-esteem as a motivation for self-care.

The workshop begins with an introspective exercise where participants acknowledge and feel the current perception of their 
self-esteem. As they engage with the tools and teachings in the process of the journey, they increase awareness and clear negativity, which allows them to become receptive and ready to make empowered changes. They then encode and integrate the changes and shift from negative to positive self-esteem with a ceremonial ritual. The last step of the process revisits the first exercise so that participants can recognize the change that has transpired during the course of the workshop. As well, the workshop provides the participants with a set of tools they can continue to use after its completion, to maintain, and enhance their new level of self-esteem.

This workshop was offered at least 12 times during a 4 year period, each time modified according to participant feedback, until a consistent design and content were established. Based on positive feedback, we decided to research the effectiveness of the workshop. Beyond a positive experience of attending the workshop, we wanted to investigate whether attendees experienced lasting change in their perception of self-esteem, and what impact this change may have had on their creative processes and in their lives.

We designed a single-blind, randomized, prospective, pilot study to evaluate the effectiveness of the "Building Confidence and Self-Esteem Workshop" on enhancing self-esteem in artists, and to evaluate the long-term effectiveness of using the recommended tools in maintaining a healthy self-esteem, as well as maintaining physical and emotional health.

\section{MATERIALS AND METHODS}

\section{Recruitment}

The Artists' Health Alliance is an organization that provides health and wellness support for artists of all disciplines in Canada. It advertised two 6-hour Building Confidence and SelfEsteem Toolbox Workshops via email to their email list serve, consisting of individual performing, and creative artists and arts organizations and unions. Workshop attendees needed to meet the criteria of professional artists, as outlined in the Canadian Artist Code (www.csarn.ca). The first 20 attendees who randomly registered for each workshop were accepted. Study subjects were randomly recruited to participate in the research study in a single-blinded fashion. Two envelopes were distributed to each workshop attendee, each containing a copy of the study consent form and a participant contact sheet. Each pair of envelopes was labeled with a pre-assigned study ID number. If a workshop attendee was interested in participating in the research study, she/he was instructed to sign both copies of the consent form and fill in both copies of the participant contact sheet, place each copy in its respective envelope and return one sealed envelope to the study coordinator. The workshop facilitators/investigators were blinded to this process so that they were unaware of which workshop attendees were participating in the study.

\section{Data Collection}

Both quantitative and qualitative data were collected for this study. As such, a Concurrent Triangulation Strategy Mixed Methods Design was used (Creswell, 2003), in which we collected quantitative and qualitative data concurrently at each of the three follow-up time-points of this study.

\section{Quantitative Data}

A validated "Self-Esteem Checkup" questionnaire was administered pre- and immediately post workshop, as well as at 2, 6, and 12 months post workshop (Schiraldi, 2001). The questionnaire aims to measure how the respondent feels at the present moment. Respondents were to rate themselves on a scale from 0 to 10 for each of the 12 statements in the questionnaire. The questionnaire also contained two closed-ended Likert scale items assessing an overall self-esteem rating score (0-100) and how restricted they felt in their daily activities because of difficulties with self-esteem (1-5) (Appendix 1).

\section{Qualitative Data}

Two open-ended questions were posed to study participants via email at 2 and 12 months following the workshop (Table 1). The qualitative data was gathered by a study coordinator who was not one of the workshop facilitators. Open-ended questions were posed with answers transcribed by the study coordinator without prompting.

At 6 months participants were invited for in-person interviews (Table 2).

\section{Data Analysis}

A mean \pm SEM score of the 12 responses in the questionnaire was calculated for the participants for each questionnaire they completed. As well, the mean response for each statement was followed over the five time points: pre-workshop, immediately

TABLE 1 | Open-ended questions posed at 2 and 12 months.

1. Do you feel that your work as an artist has been influenced by your participation in the workshop?

a) If yes, how?

b) If no, why not?

2. In what ways do you think the workshop has impacted your physical and emotional health (both positively and negatively)?

TABLE 2 | Interview Questions at 6 months.

1) What self-esteem workshop tools have you found to be the most helpful?

2) Which tools are you using on a regular basis?

a. Why, or why not?

3) What do you think would assist you to better utilize the tools presented at the workshop?

4) Do you feel that your work as an artist has been influenced by your participation in the workshop?

$$
\begin{aligned}
& \text { a. If yes, How? } \\
& \text { b. If no, why not? }
\end{aligned}
$$

5) In what ways do you think the workshop has impacted your physical and emotional health? (Both positively and negatively).

6) Any other comments? 
post-workshop, 2, 6, and 12 months post-workshop. Changes in mean scores were analyzed by a repeated measures ANOVA using SPSS 21.0. Descriptive statistics assessed normality of the data.

Responses to the open-ended questions were listed in tabular format, divided into "Yes, how?" and "No, why not?" for the first question, and categorized as positive impacts and negative impacts that the workshop has had on one's physical and emotional health for the second question, and then subsequently collapsed into more defined categories. These categories were combined into general themes with illustrative quotes.

Individual interview question responses were transcribed and coded after becoming familiar with the responses, rather than using predetermined categories. These codes and categories identified within the responses were sorted and collapsed into broader themes (Krefting, 1991).

\section{Ethics}

This study was approved by the University Health Network Research Ethics Board and written informed consent was obtained from each subject prior to any study procedures being carried out. The study was conducted in accordance with ICH guidelines.

\section{RESULTS}

Two workshops were run with study participants included. A total of 40 subjects registered for the two workshops. Nineteen from the first and 16 from the second, for a total of 35 subjects attended and consented to participate in the study. Sixteen subjects from the first, and 10 subjects from the second, for a total of 26 subjects completed all study visits. Nine subjects did not return email responses to the follow-up questionnaires.

\section{Quantitative Data}

The mean \pm SEM scores for the 12 questionnaire statements are shown in Figure 1. The pre-workshop mean score was 5.64 \pm 0.31 . All scores increased significantly immediately postworkshop and remained statistically significantly improved by the by the 3rd follow-up 12 months later. Post-workshop, the mean score was $7.54 \pm 0.19$, at 2 months $6.92 \pm 0.19$, at 6 months $6.89 \pm 0.23$, and at 12 months post-workshop the mean score was $7.32 \pm 0.22(p<0.001$ for all post-workshop times compared with pre-workshop).

The individual questionnaire statement mean \pm SEM scores for the five timepoints are shown in Figure 2. All scores increased significantly immediately post-workshop and remained statistically significantly improved by the by the $3 \mathrm{rd}$ follow-up 12 months later $(p<0.001$ for all time points compared to pre-workshop). Post-workshop scores were not significantly different from each other. Cronbach's alpha pre-workshop was 0.933 , immediately post-workshop was 0.949 , at 2 months 0.965 , at 6 months 0.579 , and at 12 months 0.545 .

The mean Self-Esteem Ratings (0-100 scale) are shown in Figure 3. The mean pre-workshop score for the participants was $49.46 \pm 3.37$. All scores increased significantly immediately postworkshop and remained statistically significantly improved by the 3rd follow-up 12 months later. Post-workshop, the mean score was $68.27 \pm 3.51$, at 2 months $63.12 \pm 3.40$, at 6 months
$63.73 \pm 4.39$, and at 12 months post-workshop the mean score was $71.15 \pm 3.61,(p<0.01$ for all post-workshop times compared with pre-workshop). Post-workshop scores were not significantly different from each other.

For the question on restriction of daily activities, there was no significant difference in responses post-workshop compared with pre-workshop.

\section{Qualitative Data}

Responses to the open ended questions were analyzed and categorized into five primary themes: group setting effective mode of presentation, positive impact on performance and creativity, transformational learning experience, integrative culminating experience, and request for refresher workshops.

\section{Theme 1: Group Setting Effective Mode of Presentation}

The group setting of the workshop provided reassurance that peers faced similar struggles as illustrated in the following quotes: "The whole sitting around in a group, and hearing other people going through the same things that you're going through, is very, very therapeutic. Like, to me, that is a tool in itself." and "I was quite pleased to be considered one of their peers. And realizing just how common this is. People that I would consider intimidating can struggle with the exact same problems."

\section{Theme 2: Positive Impact on Performance}

Participants remarked on the positive impact the workshop had on their performance and how it motivated them to take risks that they might not have taken before the workshop: "I already was booked up that day to shoot a video and I normally would not have put in my audition, but I went for it. I might not have done that. I just have to push myself to do it. My resume has bumped up a lot." Feelings of optimism and promise following the workshop were also shared: "I know I was feeling more hopeful. I think it was the idea of possibilities." "I remember [workshop facilitator] had said, you know, even if I didn't get the part, I still went. And I remember I was using that for a while. And actually, I think that's maybe permeated more than I thought into my life... where I just kinda go, "you know what? I did something." but it's like, you gotta do the little things, and so as long as you do something, it's better than nothing." "Well, it's nice to voice, yeah, where I am and, and what I want to do. It's frustrating to come back to wanting to do the same thing when I've come back to wanting to do the same thing before. It struck me that I had progressed more than I would have thought because I'd sort of, in my mind, felt I hadn't done anything, but actually, we did do a mockup of two, two books."

\section{Theme 3: Transformational Learning Experience}

Participants engaged in a partnered exercise where they had the opportunity to retell a story and allow their past perceptions of an experience to change. This was described as a transformational learning experience. Noted one participant: "The idea that you could rewrite your own story to have a different ending. Just sort of seeing it in a different perspective."

Another participant reflected on her newfound ability to disassociate the results of her work from her self-perception: "Remembering that the criticisms that other people have really have 


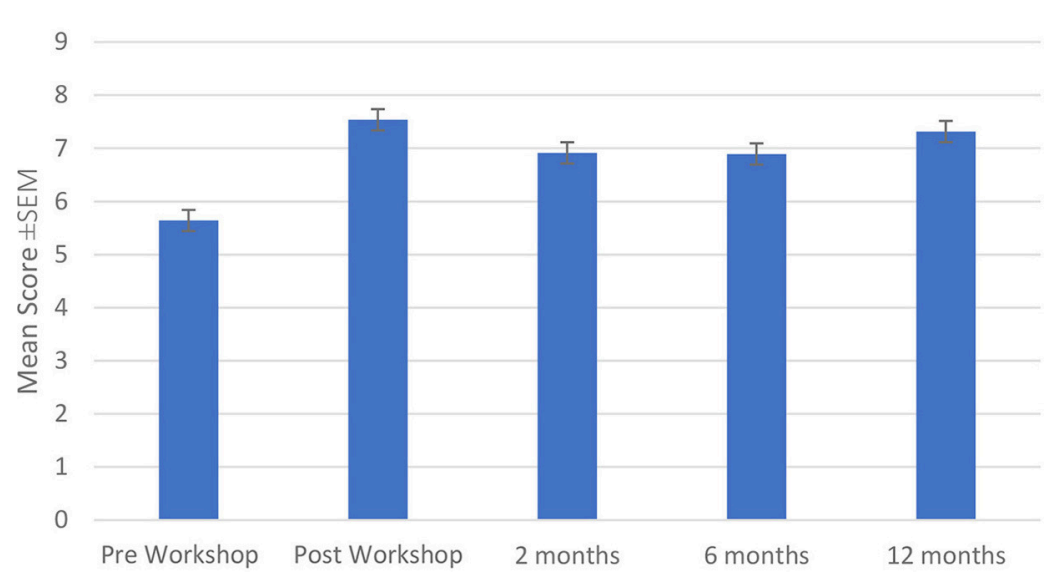

FIGURE 1 | Mean questionnaire scores.

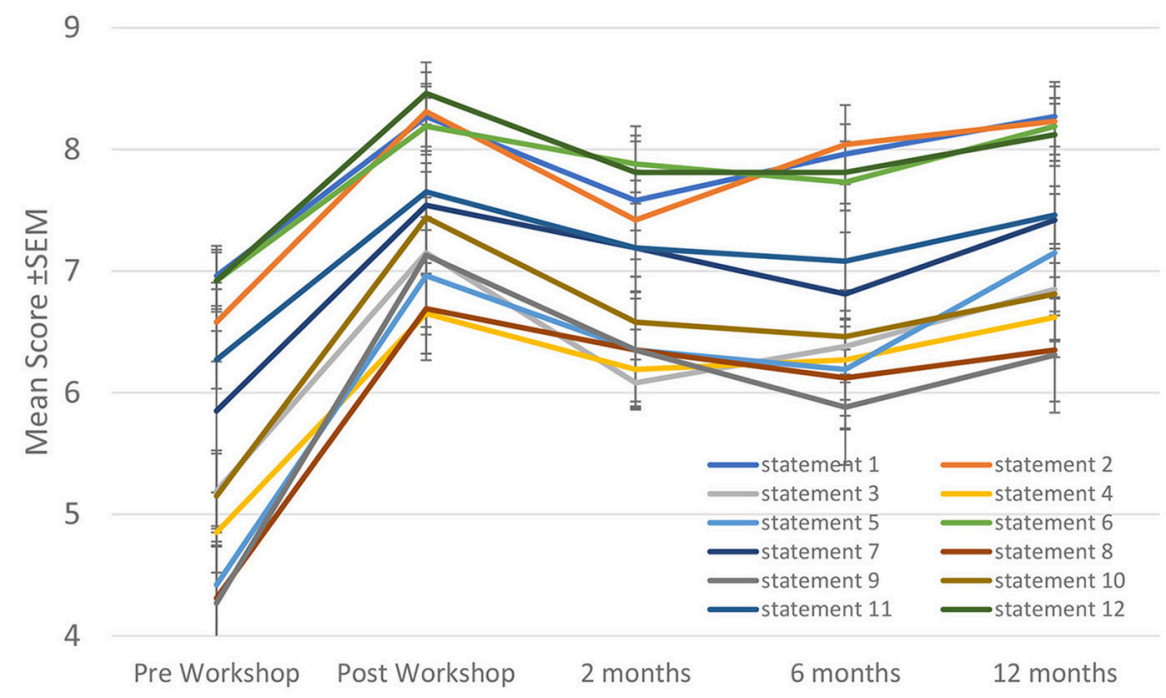

FIGURE 2 | Self-esteem questionnaire individual statement scores.

to do with them. It's that thinking well, okay, I struggle at this but, I still am a good person.”

\section{Theme 4: Integrative Culminating Experience}

Within the workshop, participants track and record what they perceive as their negative and positive attitudes, traits, and patterns. At the end of the workshop, in a ritualized experiential exercise, they throw away the negative thoughts they have recorded, and choose to pick up and keep the positive ones to review. As one participant replied: "you're writing out your negative pieces, and then, you throw it away and bring in your strengths, the pieces you wanna go forward. Seeing each piece and purging in some ways." Another said "Sometimes you don't know how much that will affect you until you do it. Cause it sounds, you know, 'okay, we're gonna put them in a... in a little pot' but it actually, it actually is very helpful in a weird way."

\section{Theme 5: Request for Refresher Workshops}

Participants expressed an interest in some type of follow-up sessions, thinking this would help support them in continuing the improvements they had learned. Three participants commented: "But in a perfect world, it could be a weekly thing where you go and it's like a maintenance thing, kind of keep in check...all your tools, all your, the things that you've learned." "It would have been great to have a check-in to prolong that effect; The workshop was not long enough..." "I don't know if this would work, especially since people have such busy schedules, but something that was over a longer period of time? Or having... not necessarily every week but... like a refresher? I don't know. Like, maybe in a couple of months, or something...even though it was a very intensive."

The experiential tools that were reported to be most useful in the workshops included: 


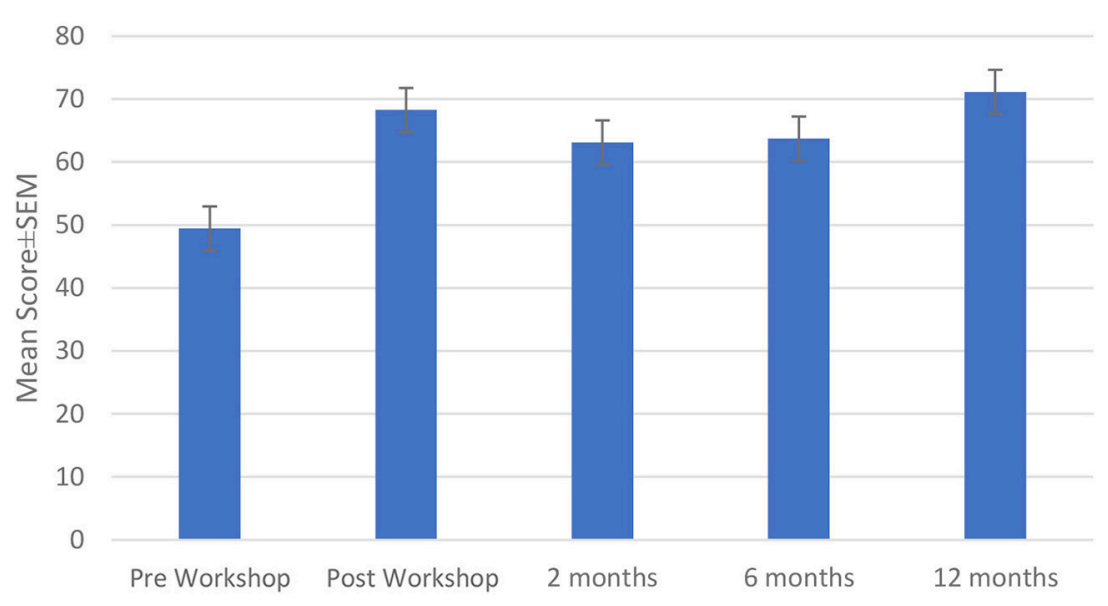

FIGURE 3 | Mean self-esteem rating scores.

Change That Story-a partner exercise where one person listens and the other repeats a personal story with the same details as many times as it takes until there is a shift in perception and experience from negative to positive.

Breathing and Guided Mediation Journey-allowing physical relaxation and suggestion to engage the participant where patterns are addressed at an unconscious and spiritual level.

Light and Dark Arrow Ritual-a group ceremony where there is integration of the workshop's experiences and learning. In an empowering act, each individual literally shoots their dark arrow and picks up a light arrow to encode and embody their changes.

Stop That Thought-a cognitive behavioral therapy exercise to enhance awareness of automatic thoughts and to allow for a new thought pattern.

Self-Care Strategies-a group discussion where behaviors are examined in the light of self-care and a useable menu of tools is created.

\section{DISCUSSION}

The results of our study suggest that the "Building Confidence and Self-Esteem Toolbox Workshop" was effective in increasing the self-esteem scores of the artist participants. They utilized tools learned in the workshop that helped them maintain this improvement over a 1-year period. Self-esteem scores improved immediately post-workshop, and remained elevated compared to pre-workshop, at 2, 6, and 12 months post-workshop. This workshop may be an effective means of addressing the issue of self-esteem in artists.

The themes that emerged from the qualitative data analysis provide further insights into some of the more effective components of the workshop.

\section{Group Setting}

Although some artistic disciplines are more socially interactive, many artists work in isolation, such as writers and visual artists. Even those who are in more social settings such as dancers, actors, and musicians can also feel isolated due to an environment of competition and comparison. Coming together with others to share in an equal way, with the same intention, in an atmosphere of trust was deemed to be therapeutic in of itself. Many respondents suggested continuing with an ongoing support group. Social isolation has been shown to be associated with low self-esteem (Leary, 1990; Leary et al., 1995).

\section{Positive Impact on Performance and Creativity}

The emergence of this theme suggests that participants experienced an internal shift as a result of the workshop, that leads to changes in behavior, improved self-esteem, and enhanced performance and creativity. Anxiety reducing techniques have been shown to increase performance (Holland et al., 2017).

\section{Transformational Learning Experience}

This theme refers to the empowerment of the "Change That Story" exercise in the workshop. This provided an opportunity to relate a personal story to a neutral listener and have the perception of self-esteem within that story change from negative to positive. This exercise requires commitment and a degree of trust due to the intimacy involved. Participants were surprised that such a profound change could occur in such a short period of time.

\section{Integrative Culminating Experience}

Participants appreciated this last element of the workshop design as a way of making the new insights and experiences physically realized with an empowering act and conscious intention to let go of the negative and embrace the positive. Creative process was engaged in making dark and light arrows imbued with meaning. Involving all the senses in this ceremonial ritual impacted the 
body mind and spirit of the participants in profound ways (Laird, 1984).

\section{Request for Refresher Workshops}

Due to the nature of this research pilot project, granting this request would have been inappropriate until the research project was completed. Despite this theme, results supported a lasting effect out to 1 year.

To the best of our knowledge, there are no reported studies specific to workshops or interventions on enhancing self-esteem for artists. There is however, support for the need for such interventions (Mann et al., 2004; Vervainioti and Alexopoulos, 2015). Indeed, in a study of dancers, the authors conclude: "dancers would benefit from programs that enhance self-esteem and reduce the negative effects of internalized shame and selforiented and socially prescribed perfectionism" (Eusanio et al., 2014).

The "Building Confidence and Self-Esteem Toolbox Workshop" was designed as an intervention to guide the artist participants in a transformative process, wherein their concepts of self could be explored and changed. The results of our study demonstrate that a shift in perception from negative to positive self-esteem can be achieved and maintained.

Many of the components, tools, and methods employed in the workshop are supported by previous studies demonstrating their ability to positively affect self-esteem. These include cognitive behavioral therapy (Thurston et al., 2017), meditation (Dahl et al., 2015; Fabiani et al., 2016; Hankey and Shetkar, 2016; Xiao et al., 2017), creative visualization (Fiske, 2017), introspective reflection and writing (Lauer and Goldfield, 1970; Chandler, 1990), selfcare mindfulness (Adimando, 2017), ceremonial ritual (Wozniak and Allen, 2012), and self-compassion and mindfulness (Galla, 2016).

There is also evidence to support the overall design and mind/body approach of the workshop (Tarantino et al., 2013; Pai, 2016; Rodkjaer et al., 2017). This intermodal intervention included synergistic use of therapeutic devices, in a safe and empathetic atmosphere which was conducive to self-learning and was reported by some participants to be a healing experience (Martin et al., 2011; Jansen and Lang, 2012).

\section{LIMITATIONS OF THE STUDY}

This was a pilot study to evaluate the effectiveness of the workshop, with a small sample size. With no previous publications of a similar workshop available, it was difficult to estimate the potential benefit and perform a power calculation to determine the appropriate sample size necessary. Thus, a larger study will be necessary to confirm these findings. As well, this was a single blind uncontrolled study where the participants were aware they were enrolled in a study, and there was no control group. Study effect could have played a role in the results. Subject participation was solicited from an email mailing list rather than totally unsolicited participation, so that selection bias may have also played a role in the results. One year follow-up may be insufficient to determine a lasting effect on self-esteem, so longer-term follow-up may be necessary to confirm the findings.

\section{Future Directions}

Although the quantitative results were highly statistically significant, a longer-term controlled study with a larger sample size should be conducted to confirm and expand on the results. With a larger sample size, a breakdown of the different artistic disciplines might shed light on differences among the different types of artists studied, so that future interventions could be more targeted if necessary. A double blind controlled study design would further reduce biases. Subsequent studies can include more detailed questioning targeting improved overall health, performance, and creativity in addition to self-esteem scores. Larger scale studies should include a validated questionnaire such as the Rosenberg Self-Esteem Scale. Given the importance of performance anxiety in artists, and its association with selfesteem, a more detailed assessment of the workshop's impact on performance anxiety would be of benefit. Future studies could include a controlled study in a larger population of artists such as a professional or university music or dance program, where some attend the workshop in their first year and others do not. All are then followed though their program for its longterm effect on their self-esteem, performance anxiety, and aspects of their emotional and physical health, and how this impacts their motivational climate (Miulli and Nordin-Bates, 2011). Once validated, many other possible applications for the workshop exist, such as inclusion of the workshop in curricula to mitigate negative consequences of low self-esteem in future artists.

\section{AUTHOR CONTRIBUTIONS}

AS conceptualized and developed the design and content of the workshop, facilitated the workshops, conceptualized the study, and developed the study protocol, wrote, reviewed, and edited the manuscript. SM was study coordinator, obtained informed consent, conducted the qualitative interviews, performed the initial data analysis, and statistical calculations, and reviewed and edited the manuscript. LG performed further detailed data analyses of the quantitative data, further statistical analyses and graphing of the data, and wrote, reviewed, and edited the manuscript.

\section{FUNDING}

This project was financially supported by the University Health Network, The Artists' Health Alliance and Healthy Dancer Canada.

\section{ACKNOWLEDGMENTS}

We wish to acknowledge the contributions of Ruth Bitorf, $\mathrm{RN}$, for her participation in facilitating and developing the workshop and the study. We acknowledge the contributions of Joseph Mpalirwa MD in the data collection for the study. 


\section{REFERENCES}

Abouserie, R. (1994). Sources and levels of stress in relation to locus of control and self esteem in university students. Int. J. Exp. Educ. Psychol. 14, 323-330. doi: 10.1080/0144341940140306

Adimando, A. (2017). Preventing and alleviating compassion fatigue through selfcare: an educational workshop for nurses. J. Holist. Nurs. 1:898010117721581. doi: 10.1177/0898010117721581

Benabou, R., and Tirole, J. (2002). Self-confidence and personal motivation. Q. J. Econ. 117, 871-915. doi: 10.1162/003355302760193913

Blascovich, J., and Tomaka, J. (1991). Measures of self-esteem," in Measures of Personality and Social Psychological Attitudes, eds J. P. Robinson, P. R. Shaver, and L. S. Wrightsman (San Diego, CA: Academic Press), 115-160.

Bodner, E., and Bensimon, M. (2008). After the curtain falls: on the postperformance adjustment of solo singers. Med. Probl. Perform. Art. 23, 172-177.

Brady, T. (2011). Exploring coaches' experience of their clients' issues of selfesteem. Int. J. Evid. Based Coach. Mentor. 5, 19-27.

Branden, N. (1994). The Six Pillars of Self-Esteem. The Definitive Work on SelfEsteem by the Leading Pioneer in the Field. New York, NY: Bantam Doubleday Dell Publishing Group, Inc.

Buckley, R. C. (2018). Aging adventure athletes assess achievements and alter aspirations to maintain self-esteem. Front. Psychol. 28:225. doi: $10.3389 /$ fpsyg.2018.00225

Chandler, G. E. (1990). A creative writing program to enhance self-esteem and self-efficacy in adolescents. J. Child Adolesc. Psychiatr. Nurs. 12, 70-78. doi: 10.1111/j.1744-6171.1999.tb00047.x

Creswell, J. D., Dutcher, J. M., Klein, W. M. P., Harris, P. R., and Levine, J. M. (2013). Self-affirmation improves problem-solving under stress. PLOS ONE 8:e62593. doi: 10.1371/journal.pone.0062593

Creswell, J. W. (2003). Research Design: Qualitative, Quantitative, and Mixed Methods Approaches, 2nd Edn. Thousand Oaks, CA: Sage Publications.

Dahl, C. J., Lutz, A., and Davidson, R. J. (2015). Reconstructing and deconstruction the self: cognitive mechanisms in meditation practice. Trends Cogn. Sci. 19, 515-523. doi: 10.1016/j.tics.2015.07.001

De Haas, G. J. F., and Winterkorn-Pierrot, C. I. C. A. (2009). Genees \& Kunst 8: Eighth biannual symposium on medical problems of dancers \& musicians, Revalidate Friesland, Beetsterzwag. Med. Probl. Perform. Art. 24, 191-196.

DeLongis, A., Folkman, S., and Lazarus, R. S. (1988). The impact of daily stress on health and mood: psychological and social resources as mediators. J. Pers. Soc. Psychol. 54,486-495. doi: 10.1037/0022-3514.54.3.486

Eades, A., Segal, D. L., and Coolidge, F. L. (2018). Suicide risk factors among older adults: exploring thwarted belongingness and perceived burdensomeness in relation to personality and self-esteem. Int. J. Aging Hum. Dev. 1:91415018757214. doi: 10.1177/0091415018757214.

Eusanio, J., Thomson, P., and Jaque, S. V. (2014). Perfectionism, shame, and self-concept in dancers: a mediation analysis. J. Dance Med. Sci. 18, 106-114. doi: 10.12678/1089-313X.18.3.106

Fabiani, V., Gatto, R. M., Tagliaferri, A., Donsante, S., Rech, D., and Pagnini, F. (2016). Awareness training for unemployed people and for welfare professionals. Med. Lav. 107, 300-306.

Fiske, E. (2017). Contemplative practices, self-efficacy and, NCLEX-RN Success. Nurse Educ. 42, 159-161. doi: 10.1097/NNE.0000000000000327

Galla, B. M. (2016). Within-person changes in mindfulness and self-compassion predict enhanced emotional well-being in healthy, but stressed adolescents. $J$. Adolesc. 49,204-217. doi: 10.1016/j.adolescence.2016.03.016

Gardner, D. G., Van Dyne, L., and Pierce, J. L. (2016). The effects of pay level on organization-based self-esteem and performance: a field study. J. Occup. Organ. Psychol. 77, 307-322. doi: 10.1348/0963179041752646

Gauthier, J., Pellerin, D., Renaud, P. (1983). The enhancement of self-esteem: A comparison of two cognitive strategies. Cogn Ther Res. 7, 389-398. doi: 10.1007/BF01187167

Hamilton, L. H., and Robson, B. (2006). Performing arts consultation: developing expertise in this domain. Prof. Psychol. Res. Pr. 37, 254-259. doi: 10.1037/0735-7028.37.3.254

Hankey, A., and Shetkar, R. (2016). Self-transcending meditation is good for mental health: why this should be the case. Int. Rev. Psychiatry. 28, 236-240. doi: 10.1080/09540261.2016.1191449
Holland, B., Gosselin, K., and Mulcahy, A. (2017). The effect of autogenic training on self-efficacy, anxiety, and performance on nursing student simulation. Nurs. Educ. Perspect. 38, 87-89. doi: 10.1097/01.NEP.0000000000000110

Hudd, S., Dumalao, J., Erdmann-Sager, D., Murray, D., Phan, E., and Soukas, N. (2000). Stress at college: effects on health habits, health status and self-esteem. Coll. Stud. J. 34, 217.

Ianucu, I., Bodner, E., and Ben-Zion, I. Z. (2015). Self esteem, dependency, self efficacy and self-criticism in social anxiety disorder. Compr. Psychiatry 58,165-171. doi: 10.1016/j.comppsych.2014.11.018

Jansen, E., and Lang, C. (2012). Transforming the self and healing the body through the use of testimonies in a divine retreat center, Kerala. J. Relig. Health 51, 542-551. doi: 10.1007/s10943-011-9564-7

Kelly, A. C., Vimalakanthan, K., and Carter, J. C. (2014). Understanding the roles of self-esteem, self-compassion, and fear of self-compassion in eating disorder pathology: an examination of female students and eating disorder patients Eating Behaviors 15, 388-391. doi: 10.1016/j.eatbeh.2014.04.008

Kenny, D. (2011). The Psychology of Music Performance Anxiety. Oxford: Oxford University Press.

Kenny, D. T., Davis, P., and Oates, J. (2004). Music performance anxiety and occupational stress amongst opera chorus artists and their relationship with state and trait anxiety and perfectionism. J. Anxiety Disord. 18, 757-777. doi: 10.1016/j.janxdis.2003.09.004

Koban, L., Shneider, R., Ahsar, Y. K., Andrews-Hanna, J. R., Landy,. L., Moscovitch, D. A., et al. (2017). Social anxiety is characterized by biased learning about performance and the self. Emotion 17, 1144-1155. doi: 10.1037/emo0000296

Krefting, L. (1991). Rigor in qualitative research: the assessment of trustworthiness. Am. J. Occup. Ther. 45, 214-222.

Kukla, A. (2007). Mental Traps: the Overthinker's Guide to a Happier Life. Toronto, ON: Anchor Canada.

Laird, J. (1984). Sorcerers, shamans and social workers: the use of ritual in social work practice. Soc. Work. 29, 123-129. doi: 10.1093/sw/29.2.123

Langendorfer, F., Hodapp, V., Kreutz, G., and Bongard, S. (2006). Personality and performance anxiety among professional orchestra musicians. J. Individ. Dif. 27, 162-171. doi: 10.1027/1614-0001.27.3.162

Lauer, R., and Goldfield, M. (1970). Creative writing in group therapy. Psychotherapy 7, 248-252. doi: 10.1037/h0086603

Leary, M. R. (1990). Responses to social exclusion: social anxiety, jealousy, loneliness, depression, and low self-esteem. J. Soc. Clin. Psychol. 9, 221-229. doi: 10.1521/jscp.1990.9.2.221

Leary, M. R., Tambor, E. S., Terdal, S. K., and Downs, D. L. (1995). Self-esteem as an interpersonal monitor: the sociometer hypothesis. J. Pers. Soc. Psychol. 68, 518-530. doi: 10.1037/0022-3514.68.3.518

Mann, M., Hosman, C. M. H., Schaalma, H. P., and de Vries, N. K. (2004). Selfesteem in a broad-spectrum approach for mental health promotion. Health Educ. Res. 19, 357-372. doi: 10.1093/her/cyg041

Marchant-Haycox, S. E., and Wilson, G. D. (1992). Personality and stress in performing artists. Pers. Individ. Dif. 13, 1061-1068. doi: 10.1016/0191-8869(92)90021-G

Martin, C. T., Keswick, J. L., Crayton, D., and LeVeck, P. (2011). Perceptions of self-esteem in a welfare-to-wellness-to-work program. Public Health Nurs. 29, 19-26. doi: 10.1111/j.1525-1446.2011.00968.x

Miller, S. R., and Chesky, K. (2004). The multidimensional anxiety theory: an assessment of and relationships between intensity and direction of cognitive anxiety, somatic anxiety, and self-confidence over multiple performance requirements among college music majors. Med. Probl. Perform. Art. 19, 12-20.

Miulli, M., and Nordin-Bates, S. M. (2011). Motivational climates: what they are, and why they matter. IADMS Bull. Teach. 3, 5-7.

Mor, S., Day, H. I., Flett, G. L., and Hewill, P. L. (1995). Perfectionism, control and components of performance anxiety in professional artists. Cognit. Ther. Res. 19, 207-225. doi: 10.1007/BF02229695

Nordin, S. M., and McGill, A. (2009). Standing on the shoulders of a young giant. How dance teachers can benefit from learning about positive psychology. IADMS Bull. Teach. 1, 4-6.

Nordin-Bates, S. M., Walker, I. J., Baker, J., Garner, J., Hardy, C., Irvine, S., et al. (2011). Injury, imagery, and self-esteem in dance healthy minds in injured bodies? J. Dance Med. Sci. 15, 76-85.

O'Dea, J. A., and Abraham, S. (2000). Improving the body image, eating attitudes, and behaviors of young male and female adolescents: a new 
educational approach that on self-esteem. Int. J. Eat. Disord. 28, 47-57. doi: 10.1002/(SICI)1098-108X(200007)28:13.0.CO;2-D

Pai, H. C. (2016). An integrated model for the effects of self-reflection and clinical experiential learning on clinical nursing performance in nursing student: a longitudinal study. Nurse Educ. Today. 45, 156-162. doi: 10.1016/j.nedt.2016.07.011

Parncutt, R., and McPherson, G. (eds.). (2002). The Science and Psychology of Music Performance: Creative Strategies for Teaching and Learning. Oxford: Oxford University Press.

Pyszczynski, T., Greenberg, J., Solomon, S., Arndt, J., and Schimel, J. (2004). Why do people need self-esteem? A theoretical and empirical review. Psychol. Bulletin. 130, 435-468. doi: 10.1037/0033-2909.130.3.435

Rickert, D. L., Barrett, M. S., and Ackermann, B. J. (2013). Injury and the orchestral environment: part 1 . The role of work organisation and psychosocial factors in injury risk. Med. Probl. Perform. Art. 28, 219-229.

Rodkjaer, L. O., Laursen, T., Seeber, K., Drouin, M., Johansen, H., Dyrehave, C., et al. (2017). The effect of a mind-body intervention on mental health and coping self-efficacy in hiv-infected individual: a feasibility study. J. Altern. Complement. Med. 23, 326-330. doi: 10.1089/acm.2016.0251

Sakellari, E., Psychogiou, M., Georgiou, A., Papanidi, M., Vlachou, V., and Sapountzi-Krepia, D. (2018). Exploring religiosity, self-esteem, stress, and depression among students of a Cypriot university. J. Relig. Health. 57, 136-145. doi: 10.1007/s10943-017-0410-4

Schellenberg, E. G. (2011). Music lessons, emotional intelligence, and IQ. Music Percept. 29,185-194. doi: 10.1525/mp.2011.29.2.185

Schiraldi, G. R. (2001). The Self-Esteem Workbook. Oakland, CA: New Harbinger Publications.

Shrier, I., and Hallé, M. (2011). Psychological predictors of injuries in circus artists: an exploratory study. Br. J. Sports Med. 45, 433-436. doi: $10.1136 /$ bjsm.2009.067751

Simmonds, J. G., and Southcott, J. E. (2012). Stage fright and joy: performers in relation to the troupe, audience, and beyond. Int. J. Appl. Psychoanal. Stud. 9, 318-329. doi: 10.1002/aps.327

Steptoe, A. (2001). "Negative emotions in music making: The problem of performance anxiety," in Series in Affective Science. Music and Emotion: Theory and Research, eds P. N. Juslin and J. A. Sloboda (New York, NY: Oxford University Press), 291-307.
Strikes, T., and Orsi, J. (1999). Song of the Deer: The Great Sundance Journey of the Soul. Malibu, CA: Jaguar Books Inc.

Tarantino, B., Earley, M., Audia, D., D'Adamo, C., and Berman, B. (2013). Qualitative and quantitative evaluation of a pilot integrative coping and resiliency program for healthcare professionals. Explore 9, 44-47. doi: 10.1016/j.explore.2012.10.002

Thurston, M. D., Goldin, P., Heimberg, R., and Gross, J. J. (2017). Self-views in social anxiety disorder: the impact of CBT versus MBSR. J. Anxiety Disord. 47, 83-90. doi: 10.1016/j.janxdis.2017.01.001

van Fenema, E. M., and van Geel, C. C. (2014). Medical problems among first year conservatory students compared with medical students. Med. Probl. Perform. Art. 29, 113-114.

Vervainioti, A., and Alexopoulos, E. C. (2015). Job-related stressors of classical instrumental musicians: a systematic qualitative review. Med. Probl. Perform. Art. 30, 197-202.

Wozniak, D. F., and Allen, K. N. (2012). Ritual and performance in domestic violence healing: from survivor to thriver through rites of passage. Cult. Med. Psyhciatry 6, 80-101. doi: 10.1007/s11013-0119236-9

Xiao, Q., Yue, C., He, W., and Yu, J. Y. (2017). The mindful self: a mindfulnessenlightened self-view. Front. Psychol. 13:1752. doi: 10.3389/fpsyg.2017. 01752

Zwaan, K., ter Bogt, T. F. M., and Raaijmakers, Q. (2010). Career trajectories of dutch pop musicians: a longitudinal study. J. Vocat. Behav. 77, 10-20. doi: 10.1016/j.jvb.2010.03.004

Conflict of Interest Statement: The authors declare that the research was conducted in the absence of any commercial or financial relationships that could be construed as a potential conflict of interest.

Copyright $\odot 2018$ Shack, Meiyappan and Grossman. This is an open-access article distributed under the terms of the Creative Commons Attribution License (CC BY). The use, distribution or reproduction in other forums is permitted, provided the original author(s) and the copyright owner(s) are credited and that the original publication in this journal is cited, in accordance with accepted academic practice. No use, distribution or reproduction is permitted which does not comply with these terms. 


\section{APPENDIX 1}

\section{Self Esteem Checkup Questionnaire}

First, rate from 0 to 10 how much you believe each of the following statements. 0 means you completely disbelieve it. 10 means you think it is completely true.

Statement

$$
\text { Rating }
$$

1. I am a worthwhile person.

2. I am as valuable a person as anyone else.

3. I have the qualities I need to live well.

4. When I look into my eyes in the mirror I have a pleasant feeling.

5. I don't feel like an overall failure.

6. I can laugh at myself.

7. I am happy to be me.

8. I am generally satisfied with the way I am developing as a person.

11. I respect myself.

12. I'd rather be me than someone else.

Next, rate your self-esteem on the following scales (Gauthier et al., 1983):

0

$$
\text { 1. }
$$

Total lack of

self-esteem of

Your Response $\quad \begin{aligned} & \text { Total fullness } \\ & \text { self-esteem }\end{aligned}$

How often do you feel restricted in your daily activities because of difficulties with self-esteem?

$\begin{array}{lllll} & 2 & 3 & 4 & 5 \\ \text { Always } & \text { Often } & \text { Sometimes } & \text { Rarely } & \text { Never } \\ \text { Your Response } & & \end{array}$

Reprinted with permission from Schiraldi. (2001). The Self-Esteem Workbook. Oakland, CA: New Harbinger. @2001 Glenn R. Schiraldi, Ph.D. Not to be reproduced without written permission 